\title{
Novel Fibrous Silica-Copper Sulfide Nanocomposite (KCC1-CuS): Synthesis and Enhanced Photocatalytic Degradation of Humic Acid
}

Neda Mohammadi

Birjand University of Medical Sciences

Ali Allahresani

University of Birjand

Ali Naghizadeh ( $\sim$ al.naghizadeh@yahoo.com )

Birjand University of Medical Sciences https://orcid.org/0000-0002-3015-2609

\section{Research Article}

Keywords: Humic acid, Photocatalytic degradation, Fibrous silica-copper sulfide nanocomposite

Posted Date: February 22nd, 2021

DOI: https://doi.org/10.21203/rs.3.rs-157129/v1

License: (c) (i) This work is licensed under a Creative Commons Attribution 4.0 International License.

Read Full License 
Novel fibrous silica-copper sulfide nanocomposite (KCC1-CuS): synthesis and enhanced photocatalytic degradation of humic acid Neda Mohammadi ${ }^{a}$, Ali Allahresani ${ }^{b}$, Ali Naghizadeh ${ }^{* c}$

$5 \quad{ }^{a}$ Department of Environmental Health Engineering, Student Research Committee, Faculty of Health, Birjand University of Medical Sciences, Birjand, Iran

${ }^{b}$ Department of Chemistry, Faculty of Science, University of Birjand, Birjand, Iran

${ }^{*} \mathrm{c}$ Medical Toxicology and Drug Abuse Research Center (MTDRC), Birjand University of Medical Sciences,

* Corresponding Author: al.naghizadeh@yahoo.com 


\section{Abstract}

The present study aims to test the degradation ability of $\mathrm{KCC}-1 / \mathrm{CuS}$ nanocomposite as a new photocatalyst for Humic acid (HA) degradation. The degradation process was accomplished using a photocatalytic reaction under irradiation by UV light. Structural characteristics of synthesized nanoparticles were done using Fourier transform infrared spectroscopy (FTIR), transmission electron microscopy (TEM), X-ray diffraction (XRD), thermogravimetric analysis (TGA), energydispersive X-ray spectroscopy (EDX). Furthermore, the effect of important degradation variables such as $\mathrm{pH}$ (3-11), nanocatalyst dosage (0.005-0.1 g/L), HA concentration (2-15 mg/L), and contact time (0-90 $\mathrm{min})$ were investigated. SEM and TEM images showed that the size of KCC$1 / \mathrm{CuS}$ nanocomposite was approximately $50 \mathrm{~nm}$. According to the results of the study, the maximum degradation of HA was $89.5 \%$ in the photocatalytic degradation process of HA by KCC1/CuS nanocomposite under UV light at the optimum condition of $\mathrm{pH}=3$, nanocomposite dose of $0.1 \mathrm{~g} / \mathrm{L}, \mathrm{HA}$ concentration of $2 \mathrm{mg} / \mathrm{L}$ and contact time of $90 \mathrm{~min}$.

Key Words: Humic acid, Photocatalytic degradation, Fibrous silica-copper sulfide nanocomposite

\section{Introduction}

The problem of water pollution is a major environmental issue. In recent years many pollutants enter the water as a result of urbanization and industrialization, and as a result, worldwide attention has been focused on controlling water pollution (Reddy \&Lee 2013). Water resources worldwide contain natural organic matter (NOM) resulting from the interaction between the geosphere, hydrosphere, and biosphere (Murray \&Parsons 2004). The presence of humic acid as a NOM in water resources could be affect water quality by increasing coagulants and disinfectants, and producing complex material in distribution systems, as well as providing a basis for the production of disinfection by-products (Kabsch-Korbutowicz et al. 2008). Humic acid consists of two hydrophobic and hydrophilic parts, and contains functional groups such as $-\mathrm{C}=\mathrm{O},-\mathrm{COOH}$, and - 
$\mathrm{OH}$ related to the aliphatic and aromatic part of the molecule (Ngah et al. 2011). Humic substances make up 50-80\% of the organic matter in soil and water, and made up of carbon, hydrogen, oxygen, nitrogen, and sometimes sulfur (Jones \&Bryan 1998). As the concentration of humic acid in the aquatic environment increases, it changes the properties of water such as odor, taste, and color (Liu et al. 2016). Humic acid molecules can bind strongly to heavy metals and synthetic organic matter, making it difficult to remove contaminants from the water (Li et al. 2011). Also, reaction of HA with chlorine in drinking water intensifies the production of carcinogenic by-products (Bolto et al. 2004). Although HA compounds are not carcinogenic by themselves, they produce secondary problems during the process of purifying drinking water, including changing taste, color, and odor (Fearing et al. 2004), adverse effects on membrane function (Fan et al. 2002), corrosion of metal facilities (Yoon \&Lueptow 2005), re-growth of microorganisms in the water supply system and water storage tanks (Panyapinyopol et al. 2005), and increase the use of disinfectants in water treatment. During the disinfection process, HA compounds can react with disinfectants and create more than 600 types of disinfectant by-products, such as haloacetic acids and trihalomethanes, which can cause cancers including colon cancer and bladder cancer (Matilainen et al. 2010). The removal of HA in drinking water is carried out by various processes, including adsorption, coagulation, advanced oxidation, membrane processes, ion exchange, chitosan polymers (Doulia et al. 2009), and photocatalysis (Liu et al. 2008). In many areas of the world, before chlorination, HA is removed by various processes, including coagulation followed by filtration. Although the coagulation process eliminates HA, it creates many underlying problems, including high sludge production with alum as well as high operation cost (Mesdaghinia et al. 2006). Among these methods, the advanced oxidation process appears to be more suitable for the treatment of waters containing NOM (Yang \&McGarrahan 2005). 
In the last decade, advanced oxidation processes as a suitable high-performance method for HA elimination have been the focus of many researchers. The methods used in advanced oxidation processes include ultrasound, electro-Fenton, photo-Fenton, ozonation, UV/ozone, electro/persulfate, ultrasonic/persulfate, photocatalytic, etc. The benefits of these processes include the production of free radicals with high oxidation potential, high efficiency in breaking down organic matter, low start-up costs, and variability in methods (Hou et al. 2013, Kang et al. 2016). Photocatalytic purification of various pollutants by use of radiation in the presence of a suitable photocatalyst can damage and degrade the pollutants and transform them into safe byproducts as well as reduce the purification steps. The mechanism of the photocatalytic process involves the irradiation of ultraviolet light to the semiconductor material and subsequent electron excitation from the valence band to the conduction band, and this electron excitation produces hydroxyl radical in aqueous solutions (KordMostafapour et al. 2016). Various semiconductor materials have been used to investigate the photocatalytic properties, including metal oxides and metal sulfides such as (Asgari et al. 2011) $\mathrm{CuS}$ (Isac et al. 2019) $\mathrm{CdS}$ (Zhang et al. 2019) $\mathrm{WO}_{3}$ (Liu et al. 2019) $\mathrm{ZnO}$, (Oskoei et al. 2016) $\mathrm{TiO}_{2}$ (Schneider et al. 2014). Copper sulfide (CuS) is a semiconductor that is non-toxic, inexpensive, accessible, and sustainable in the environment. Copper sulfide with $2.0 \mathrm{~V}$ band gap is also an important semiconductor material which is very effective in terms of physical, chemical, electrical, magnetic properties. In recent years, materials with organic-metal bonds such as $\mathrm{CuS}$, have received considerable attention due to their high photocatalytic potential in the presence of ultraviolet radiation to remove organic compounds from aquatic environments. Fibrous silica KAUST Catalysis Centre $\mathrm{KCC}-1$ has a unique fiber morphology and also a high level of thermal and mechanical stability so it offers excellent execution in contrast with different sorts of silica, making it ideal for use as sorbent applications (Polshettiwar et al. 2010). It has been successfully used in a variety of applications, such as $\mathrm{CO}_{2}$ 
capture, photocatalysis, DNA and gene transfer, hydrogenesis reactions, and hydrothermal reactions (Fihri et al. 2012, Huang et al. 2014).

In this study, KCC-1/CuS nanocomposite was synthesized for the first time and used for HA degradation from aqueous solutions. To improve the efficiency of the nanocomposite in pollutant degradation, parameters such as solution $\mathrm{pH}$, contact time, nanoparticle dose, and HA concentration were studied.

\section{Materials and Methods}

\subsection{Chemicals}

The chemicals used in this study to synthesize the $\mathrm{KCC}-1 / \mathrm{CuS}$ nanoparticles were cetyltrimethylammonium bromide $\left(\mathrm{C}_{19} \mathrm{H}_{42} \mathrm{BrN}\right)$, urea $\left(\mathrm{CH}_{4} \mathrm{~N}_{2} \mathrm{O}\right)$, tetraethyl orthosilicate, TEOS $\left(\mathrm{SiC}_{8} \mathrm{H}_{20} \mathrm{O}_{4}\right)$, cyclohexane $\left(\mathrm{C}_{6} \mathrm{H}_{12}\right)$, 1-pentanol $\left(\mathrm{C}_{5} \mathrm{H}_{12} \mathrm{O}\right)$, ethanol $\left(\mathrm{C}_{2} \mathrm{H}_{5} \mathrm{OH}\right)$, Copper(II) sulfate $\left(\mathrm{CuSO}_{4}\right)$, ethylene glycol $\left(\mathrm{C}_{2} \mathrm{H}_{6} \mathrm{O}_{2}\right)$, and sodium thiosulfate $\left(\mathrm{Na}_{2} \mathrm{~S}_{2} \mathrm{O}_{3}\right)$. All chemicals were purchased from Merck Co. (Germany) and were used without further purification.

\subsection{KCC-1/CuS synthesis and characterization}

\subsubsection{Synthesis of KCC-1 nanoparticles}

To synthesis of KCC-1 nanoparticles, $2.0 \mathrm{~g}$ of triethylmethyl ammonium bromide and $2.4 \mathrm{~g}$ of urea were dissolved in $100 \mathrm{ml}$ of water and was placed on a mixer for 15 minutes. Then $10 \mathrm{ml}$ of TEOS was mixed with $10 \mathrm{ml}$ of cyclohexane. This solution was added dropwise to the previous solution and placed on the stirrer again for 15 minutes. After that, $6 \mathrm{ml}$ of 1-panthenol was added to the solution and was placed at room temperature on the stirrer for 20 minutes. It was then placed in an oven at $120^{\circ} \mathrm{C}$ for $1 \mathrm{~h}$ and was allowed to settle at room temperature (Dhiman et al. 2015).

\subsubsection{Synthesis of $\mathrm{KCC}-1 / \mathrm{CuS}$ nanocomposite}

Copper sulfate was used to modify the surface of KCC-1 nanoparticles. First, $0.15 \mathrm{~g}$ amount of KCC-1 nanoparticles was dispersed in ethylene glycol solvent $\left(120^{\circ} \mathrm{C}\right)$, and copper sulfate was 
106

107

108

109

110

111

112

113

114

115

116

117

118

119

120

121

122

123

124

125

126

127

128

129

added to it. After dissolving the copper sulfate in the above solution, the sodium thiosulfate solution was added, and the reaction mixture was refluxed at $90{ }^{\circ} \mathrm{C}$ for $90 \mathrm{~min}$. The resulting nanocomposite was then separated by centrifugation, rinsed with deionized water and ethanol several times, and dried in a vacuum oven for 8 hours (Beyki et al. 2016).

\subsubsection{Characteristics of the synthesized nanocomposites}

Different analysis was utilized to identify the surface morphology and structural characteristics of the synthesized KCC-1/CuS nanocomposite. Transmission electron microscopy (TEM) and field emission-scanning electron (FE-SEM) with high-resolution micrographs were applied to characterize the morphology, size and shape of the nanoparticles. The Fourier transform infrared (FT-IR) analyses were applied to investigate the functional groups. XRD analysis was used to determine the crystalline structure of the components of the sample, while EDS was used to find out the elemental composition of the sample.

\subsection{Experiments}

According to Scheme 1, the reactor used in this study consists of two parts. The main enclosure (reaction enclosure) where all the testing procedures are carried out. The secondary enclosure, which surrounds the main chamber and reduces the temperature of the UV-C radiation compartment by the continuous flow of water.

The lamp used as a radiation source was UV-C with a power consumption of 18 watts, a generated wavelength of $253.7 \mathrm{~nm}$, a lifespan of 8000 hours and a radiation intensity of 282-294 $\frac{\mathrm{W}}{\mathrm{m}^{2}}$. The length of the lamp was $22 \mathrm{~cm}$, which was placed in a quartz sheath with a diameter of $5 \mathrm{~cm}$ in the center of the reactor (Scheme 1).

The removal efficiency of $\mathrm{HA}$ in the photocatalytic process using $\mathrm{KCC}-1 / \mathrm{CuS}$ nanocomposite was tested as a function of different solution $\mathrm{pH}$ values $(3,5,7,9,11)$, nanocomposite dosage $(0.005$, 
131 time (10, 20, 40, 60 and $100 \mathrm{~min})$. All these experiments were conducted using $300 \mathrm{~mL}$ flasks and

132 mixing speed of $300 \mathrm{rpm}$. Before starting the photocatalytic process under UV light, the flasks

133 were on the dark condition for about $30 \mathrm{~min}$ to determine the adsorption/desorption equilibrium.

134 After this step the concentration of HA measured using UV spectrophotometer (T80, UV/Visible,

135 United Kingdom) at a spectral peak of $254 \mathrm{~nm}$ and considered as intial concentration. After specific

136 times of light rediation, the HA concentarion was measured again and considered as secondary

137 concentration. The HA removal efficiency $(\% \mathrm{R})$ were determined using the following equation:

140 Where $\mathrm{C}_{0}$ and $\mathrm{C}_{\mathrm{t}}$ are the measured HA concentrations $(\mathrm{mg} / \mathrm{L})$ before photocatalytic process and 141 after specific time of it.

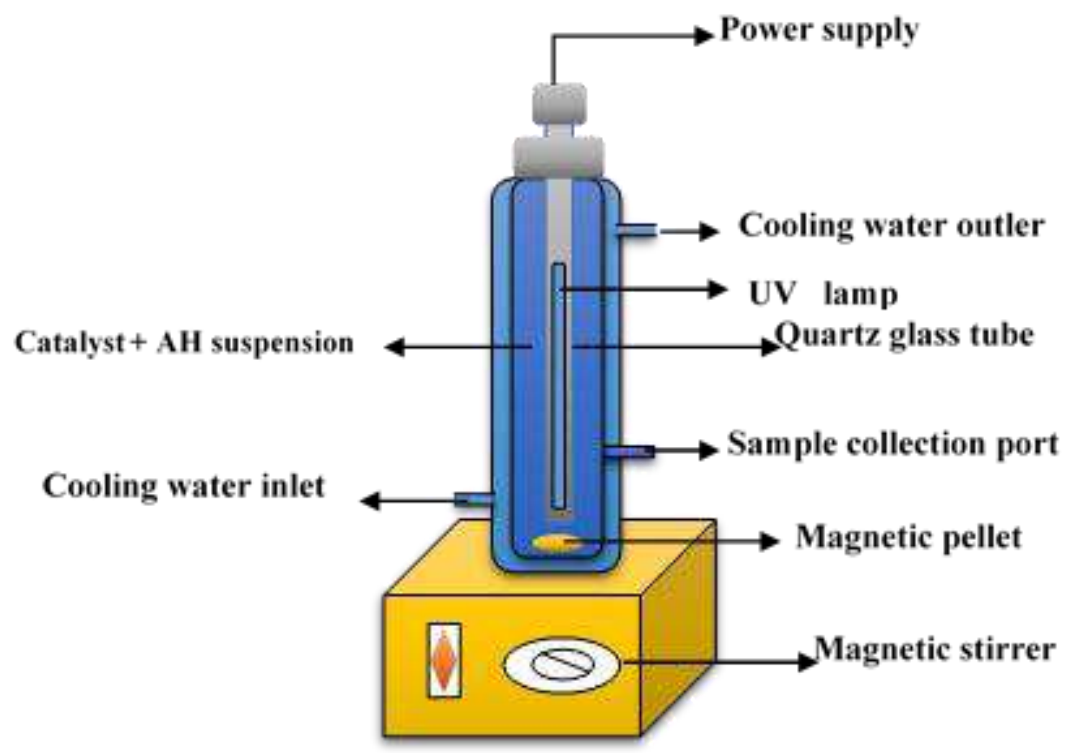

144 Scheme 1. Schematic representation of the reactor used for the photocatalytic degradation of HA. 


\section{Results and discussion}

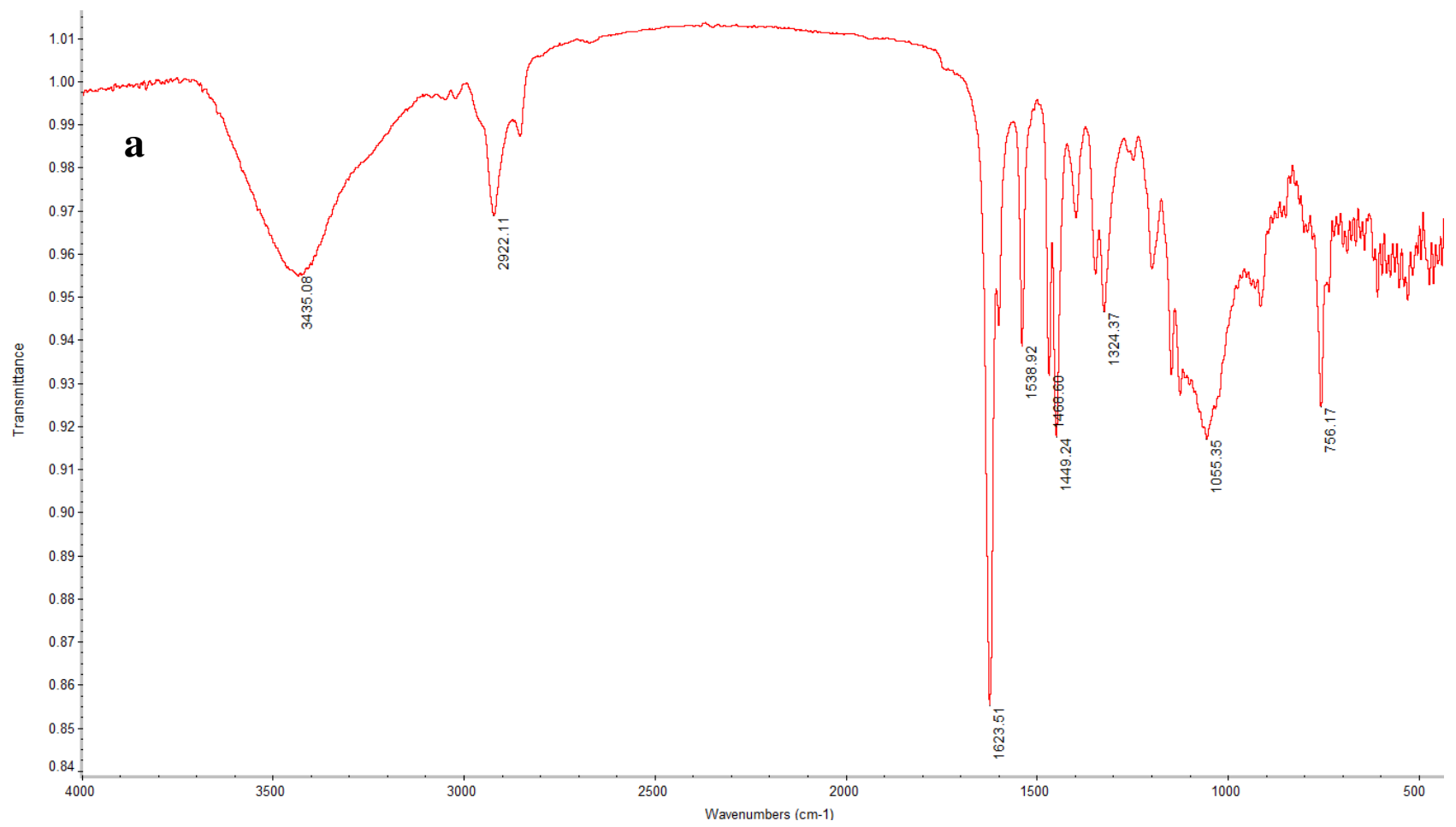




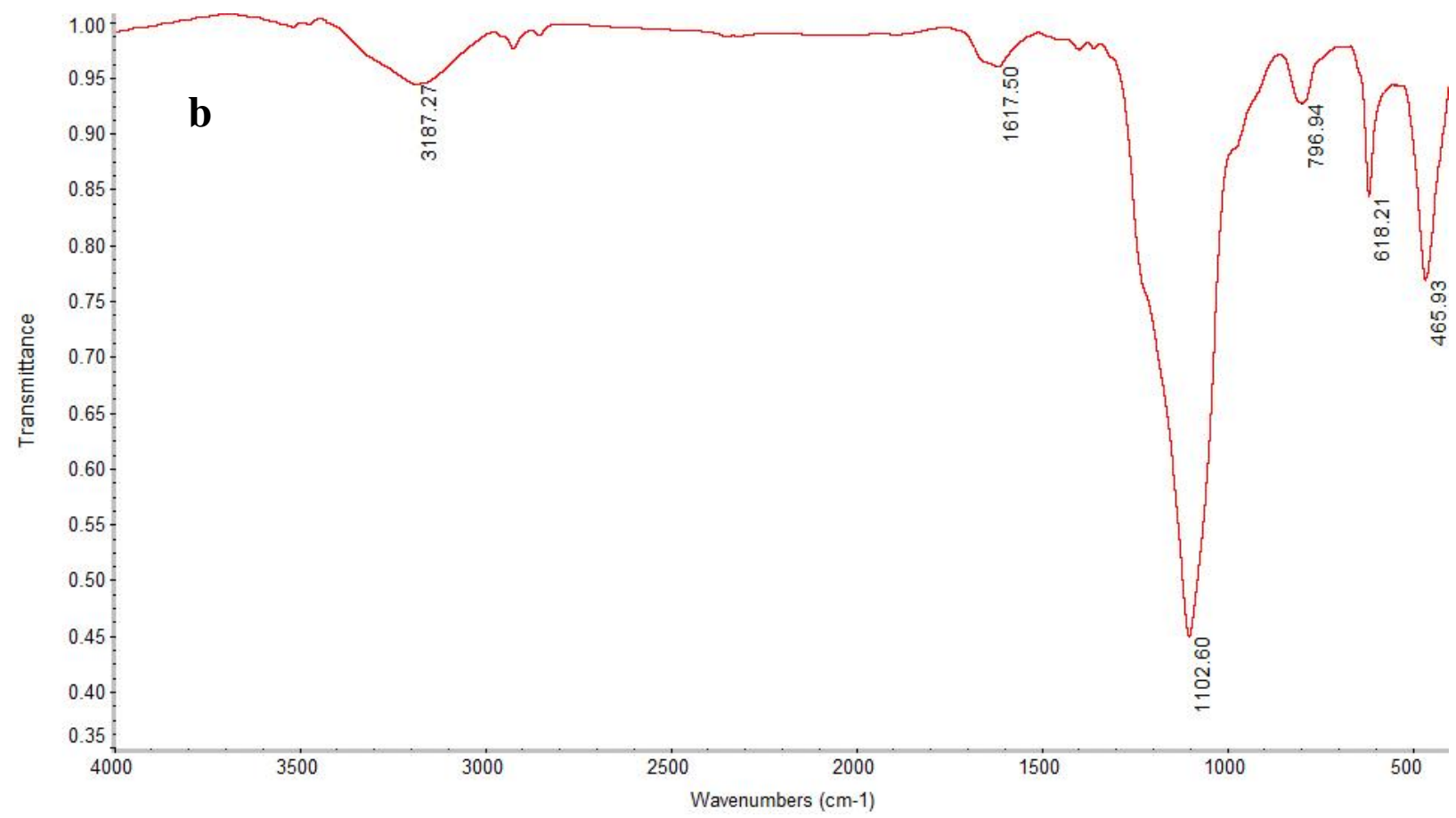

Fig. 1. FTIR spectrums of KCC-1 (a) and KCC-1/CuS (b) nanocomposite

162

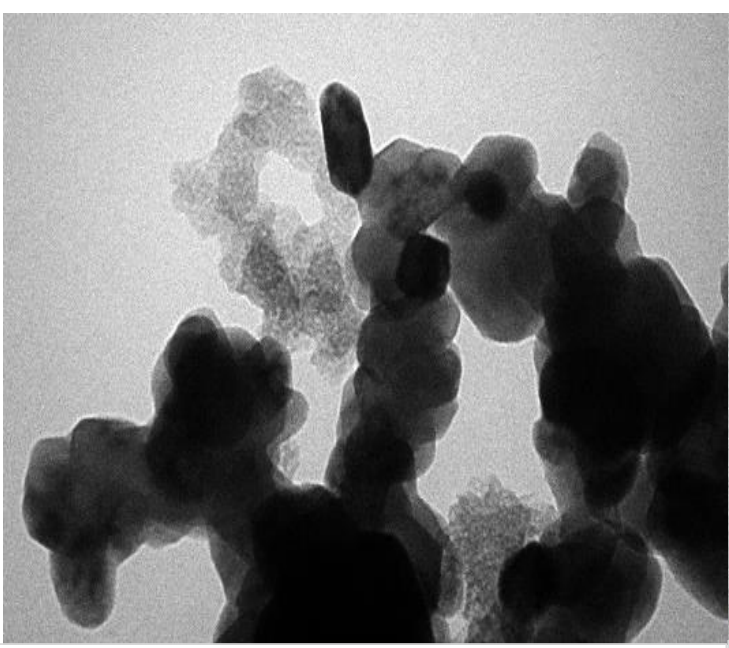

$100 \mathrm{~nm}$

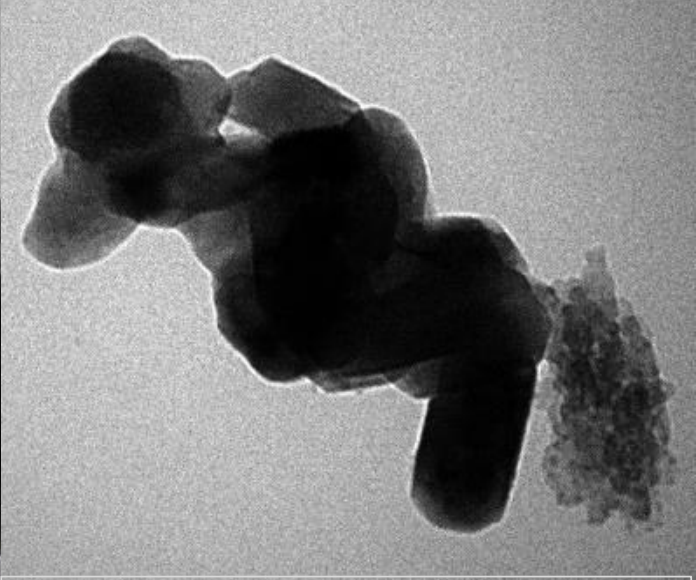

$100 \mathrm{~nm}$ 
177 between $30{ }^{\circ} \mathrm{C}$ and $100{ }^{\circ} \mathrm{C}$, which is related to the adsorbed water molecules on the support. The attributed to the decomposition of material oxidizes, appeared at the temperature range of 300-

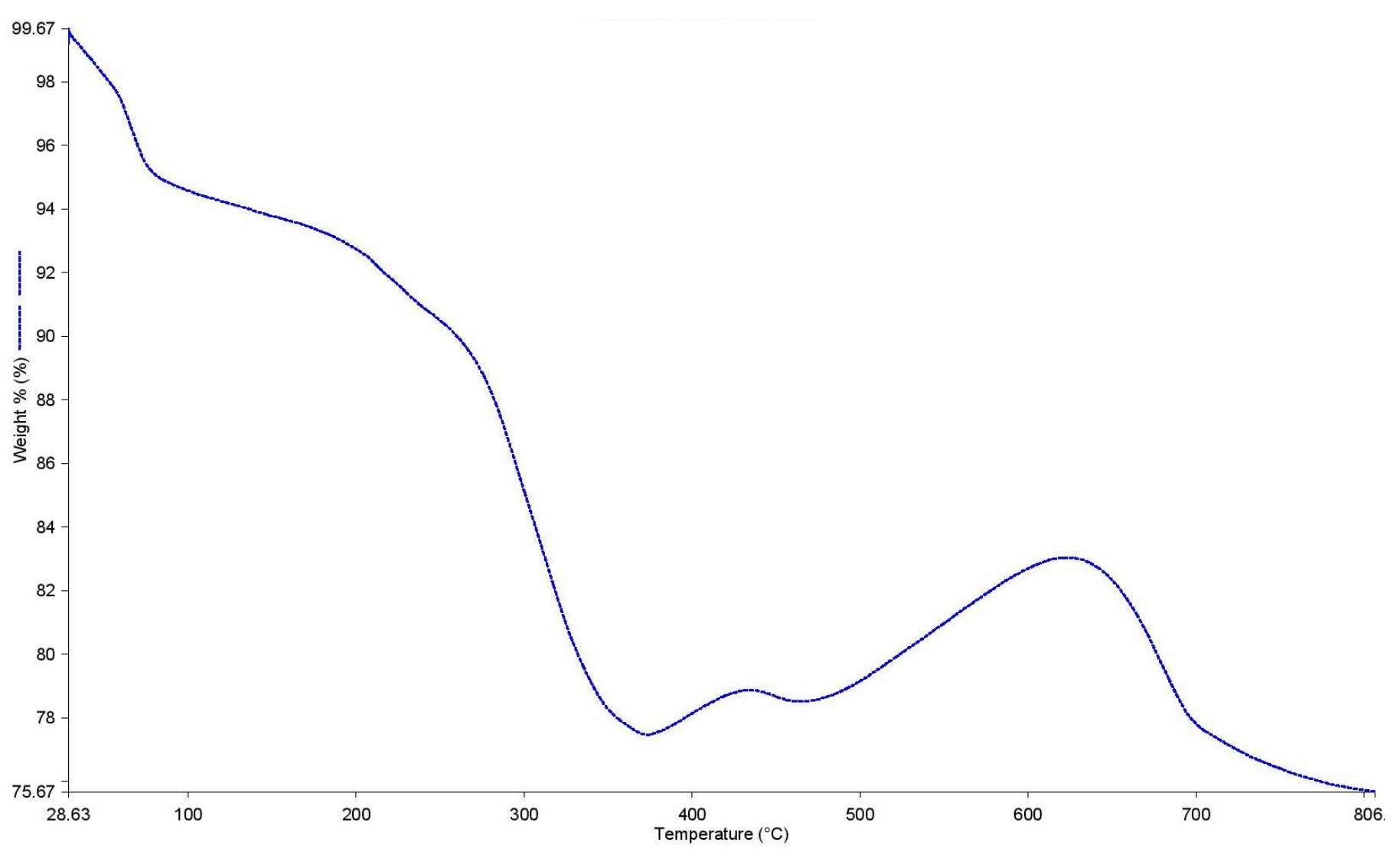

Fig.3. TGA analysis of KCC-1/CuS nanocomposite are shown in Figure 4. According to the EDX spectrum, it is evident that elements are sort down 
187

188

189

190

191

192

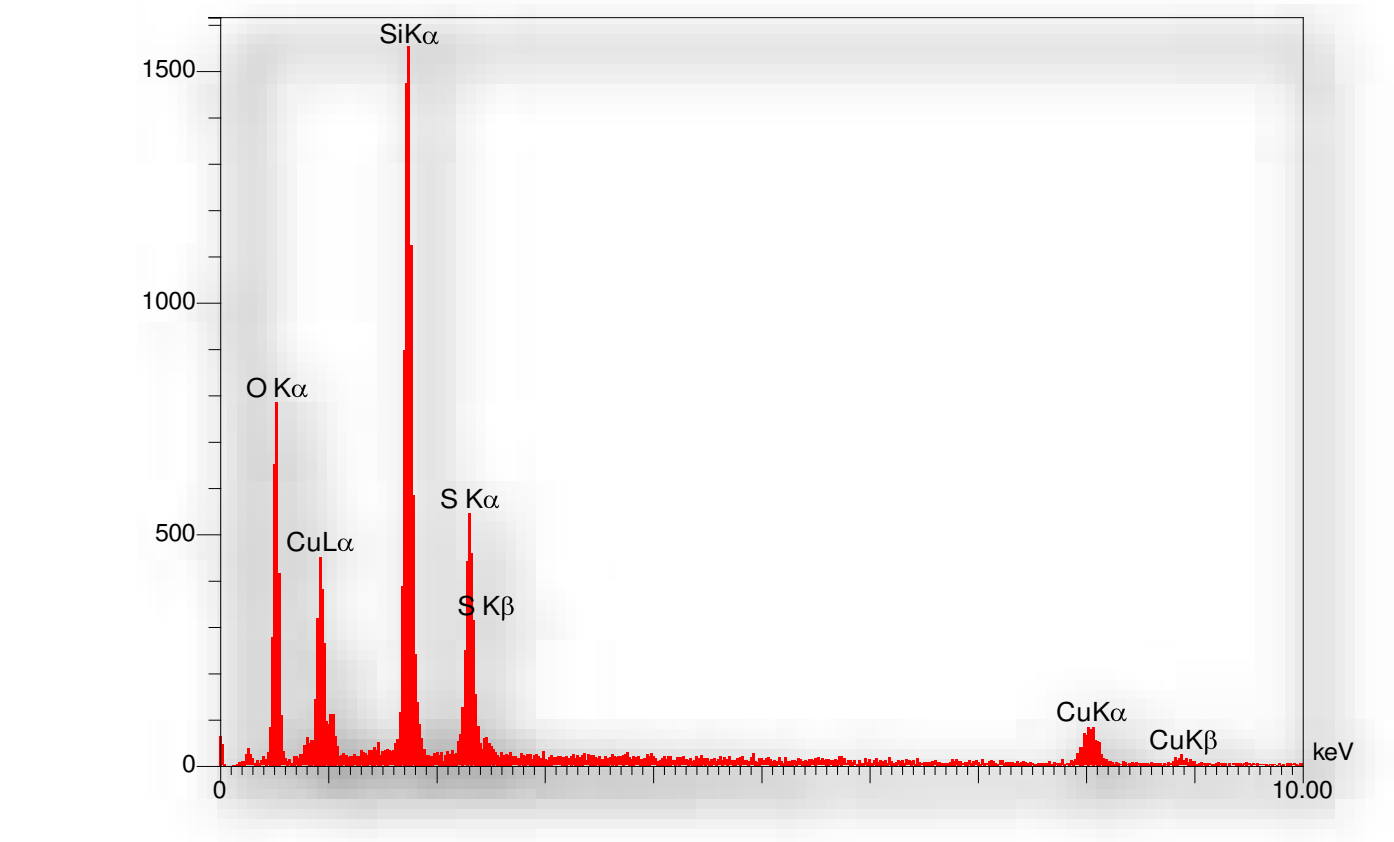

193

194

195

196

197

198

199

200

by abundance as $\mathrm{Si}, \mathrm{O}, \mathrm{S}, \mathrm{Cu}$. The formation of the $\mathrm{KCC}-1$ as the core of the nanocomposite can be concluded from the presence of $\mathrm{Si}$ and $\mathrm{O}$ that are detected at 0.5 and $1.7 \mathrm{keV}$, respectively. In addition, the presence of $\mathrm{Cu}$ and $\mathrm{S}$ with a high ratio confirms the $\mathrm{CuS}$ coating (outer shell) onto $\mathrm{KCC}-1$ particles to form KCC-1/CuS MNC.

92

Fig.4. EDS results of KCC-1/CuS nanocomposite

As shown in Figure 5 the XRD pattern was performed from $9.0^{\circ}(2 \theta)$ to $79.0^{\circ}(2 \theta)$ to confirm the crystallinity of the synthesized nanocomposite. Also, using this analysis is proportional to obtain more information about the molecular structures of the synthesized nanocomposite. Strong and sharp scattered peaks indicate that the resulting nanocomposite is very crystalline. The two sharp peaks at $2 \theta \approx 32^{\circ}$ and $2 \theta \approx 48^{\circ}$ are related to the crystalline parts. The average crystallite size of KCC-1/CuS was also calculated via XRD analysis using Debye-Scherrer's equation: 
$201 \quad \mathrm{D}=\frac{k \lambda}{\beta \cos \theta} \quad$ Eq. 2

202 Where $\mathrm{D}$ is the diameter of particles, $\lambda$ is the wavelength of $\mathrm{X}$-ray radiation $(\lambda=0.154 \mathrm{~nm}), \beta$ is full 203 width at half maxima (FWHM), and $\theta$ is Bragg's angle (Rahimi et al. 2020). The average 204 crystalline size was calculated to be $50 \mathrm{~nm}$, which was further confirmed from TEM.

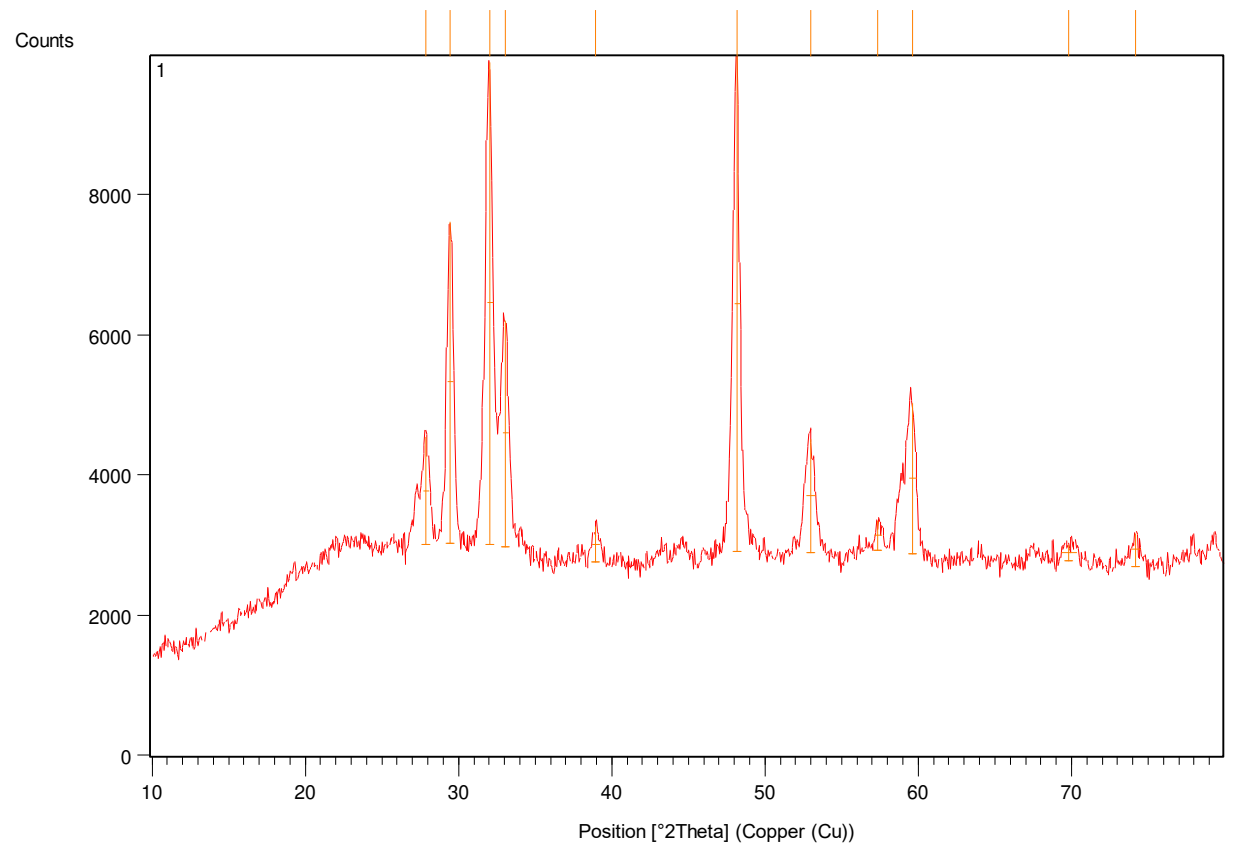

205

Fig.5. XRD patterns of 7 KCC-1/CuS NPs

\subsection{The impact of solution pH}

The solution's $\mathrm{pH}$ has a significant effect in the photocatalytic processes, which may affect the

209 cycle of degradation of organic molecules in many ways. The two most significant considerations

210 are the quality of breakdown of polluting molecules and the surface charge of the catalyst used.

211 Accordingly, the surface charging of the catalyst may be examined by evaluating the pHpzc (the 212 point of zero charge) value. In this way, the pHzpc determination study was applied. The pHpzc 213 of $\mathrm{KCC}-1 / \mathrm{CuS}$ NPs is obtained to be 5.3 (Fig.6.a). When the solution $\mathrm{pH}$ is greater than 5.3 value, 
214 the surface of nanoparticles would have negative charges resulting from surplus $\mathrm{OH}^{-}$ions. From 215 another side, when the solution $\mathrm{pH}$ is less than 5.3 value, the surface of nanoparticle will be 216 positively charged, producing $\mathrm{H}^{+}$protons. HA has both hydrophobic and hydrophilic functional 217 groups such as the carboxyl, phenolic hydroxyl, alcoholic hydroxyl, and carbonyl forms. As shown 218 in Figure $6 \mathrm{~b}$ the HA degradation efficiency is reduced at alkanoic pHs because of the high 219 repulsion of negatively charged carboxylate ions form of nanocomposite (Wiszniowski et al. 2003). The maximum degradation efficiency of HA equal to $49.5 \%$ recorded at $\mathrm{pH}=3$. This is

221 because the surface charge of the catalyst is positive at $\mathrm{pHs}$ lower than pHzpc. So the 222 nanocomposite can react more effectively to hydroxyl groups of HA in the solution. The results of another study on efficiency of photocatalytic degradation of humic acid using magnetic 224 nanoparticles (Fe-doped $\mathrm{TiO} 2 @ \mathrm{Fe} 3 \mathrm{O} 4)$ showed that the efficiency of humic acid removal increased under acidic conditions and reached its maximum at $\mathrm{pH} 3$, but decreased at basic and neutral pH values (Moein et al. 2020).

227
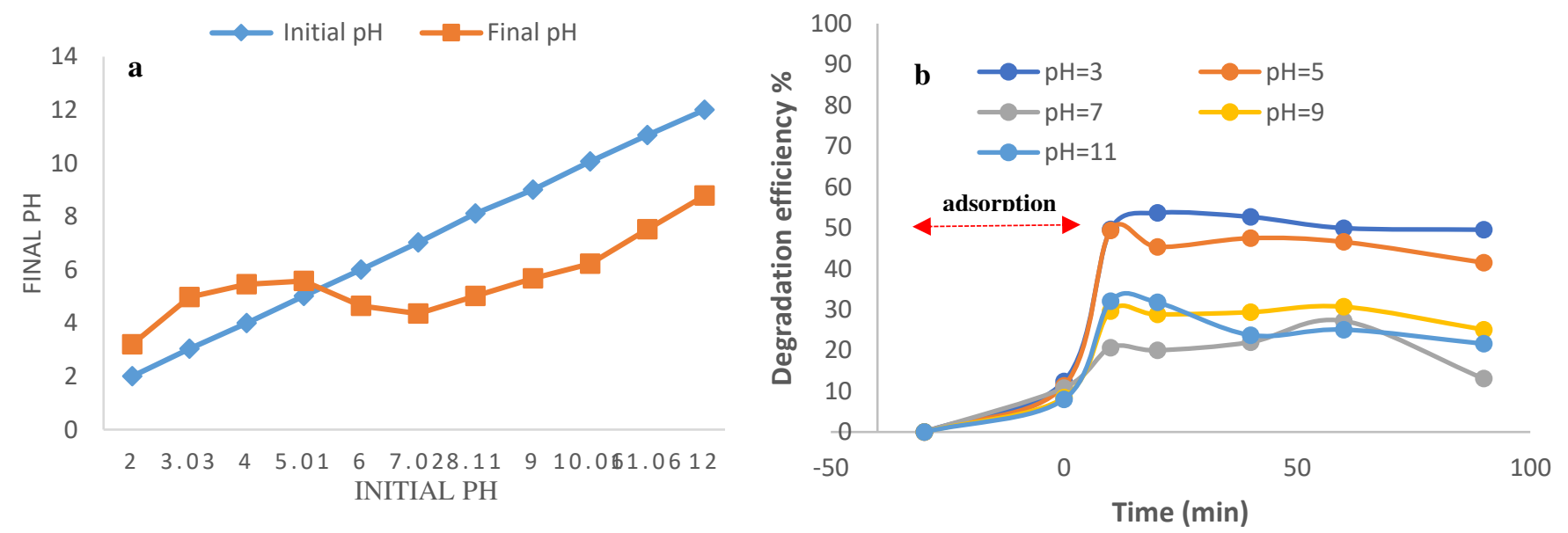

Fig.6. a) The $\mathrm{pH}_{\mathrm{zpc}}$ of $\mathrm{KCC}-1 / \mathrm{CuS}$ nanocomposite b) Effect of $\mathrm{pH}$ in photocatalytic degradation of HA by KCC-1/CuS (HA concentration: $15 \mathrm{mg} / \mathrm{L}$, catalyst dosage: $0.03 \mathrm{~g} / \mathrm{L}$ ). 


\subsection{The impact of Catalyst dose}

233 The effect of catalyst dose on the degradation efficiency of HA in the range of 0.005 to $0.1 \mathrm{~g} / \mathrm{L}$

234 was investigated. According to the results shown in Figure 7, increasing the KCC-1/CuS dose 235 leads to increasing the efficiency of HA degradation. The highest decomposition efficiency was 236 observed in the nanocomposite dose of $0.1 \mathrm{~g} / \mathrm{L}$, so that the degradation efficiency of $88.6 \%$ is 237 achieved in 90 minutes. Increasing the efficiency of photocatalytic removal of HA by increasing 238 the amount of catalyst dose in this study can be explained by increasing the available surface area 239 and the number of active sites at the catalyst surface (to absorb optical photons). Therefore, upon 240 UV irradiation, more electron holes are produced, which leads to an increase in the presence of 241 oxidizing radicals and the degradation of HA. The same results are reported by Eslami et al.(2015) 242 that with increasing the catalyst dosage of $\mathrm{N}, \mathrm{S}$ co-doped $\mathrm{TiO}_{2}$ from 0.5 to $2 \mathrm{~g} / \mathrm{L}$, the non-steroidal 243 anti-inflammatory ibuprofen degradation increased from $42 \%$ to $85 \%$ (Eslami et al. 2016).

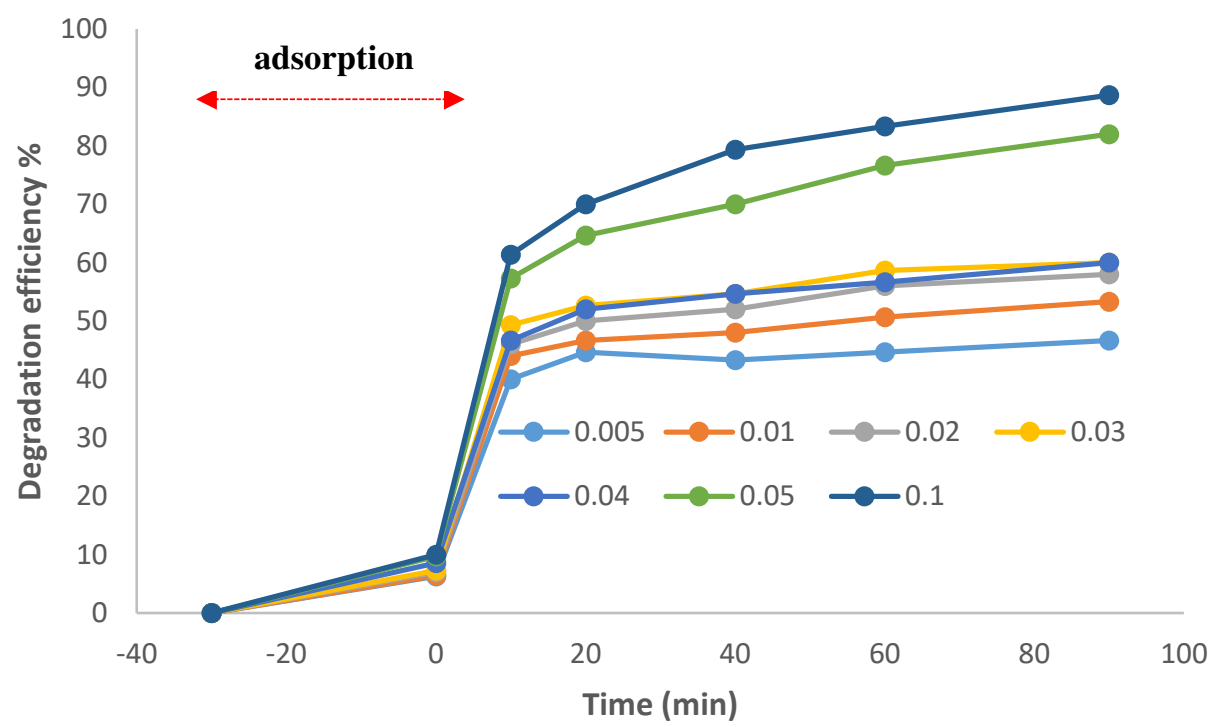

Fig. 7. Effect of catalyst dosage in photocatalytic degradation of HA by 


\subsection{The impact of HA concentration and contact time}

The initial concentration of contaminants is another important factor in the efficiency of UV/ KCC$1 / \mathrm{CuS}$ process. In this study, the effect of the HA concentration of $2-15 \mathrm{mg} / \mathrm{L}$ was investigated on the HA degradation (other parameters were constant at the optimized values of $\mathrm{pH}=3$, catalyst dose of $0.1 \mathrm{~g} / \mathrm{L}$ ), and the results have been shown in Fig 8. Results indicate that increasing the HA concentration from 2 to $15 \mathrm{mg} / \mathrm{L}$ led to a reduction in efficiency of the process from $89.5 \%$ to $17.3 \%$ at a reaction time of $90 \mathrm{~min}$. The reason for a reduction of efficiency with the increase of HA concentration is that in lower concentrations, more active sites on the surface of nano-catalysts are available to adsorb the contaminant. But increasing the concentration of HA led to a decrease in the available surface of the catalyst and increasing the repulsive forces between them. Based on the other aspect, it can be interpreted that at higher HA concentrations, the generation of hydroxyl radicals on the surface of the catalyst reduces since the active sites of the catalyst might be saturated by the pollutant (Gnanaprakasam et al. 2015). In a study of sonophotocatalytic degradation of diazinon using $\mathrm{Fe}-\mathrm{TiO}_{2}$ nanoparticles at various initial concentrations of diazinon in aqueous solutions, Tabasideh et al. concluded that the efficiency of diazinon removal decreased with increasing the concentration of it (Tabasideh et al. 2017). Li et al. obtained a similar finding in an investigation of the photocatalytic degradation of humic acid. They found a noticeable decrease in the removal efficiency with increasing concentrations of contaminants (Li et al. 2002). Reaction time is also an important parameter that affects the process of decomposition of the pollutants regardless of the type of catalyst (homogenous or heterogeneous). So the degradation efficiency of HA was investigated in the range of 0 to 90 min of reaction time at different HA concentrations. According to Figure 8, it is obvious that for HA concentration of $2 \mathrm{mg} / \mathrm{L}$ by increasing the reaction time from 0 to $90 \mathrm{~min}$ the degradation efficiency increased from 12.0 to 89.5\%. Ghasemi et.al; observed similar results by increasing the contact time from 20 to 80 min, 
271 the furfural degradation using $\mathrm{UVC}_{\mathrm{TiO}} / \mathrm{GAC}$ composite decreased, and the irritation of $80 \mathrm{~min}$ 272 was considered as the optimum value.

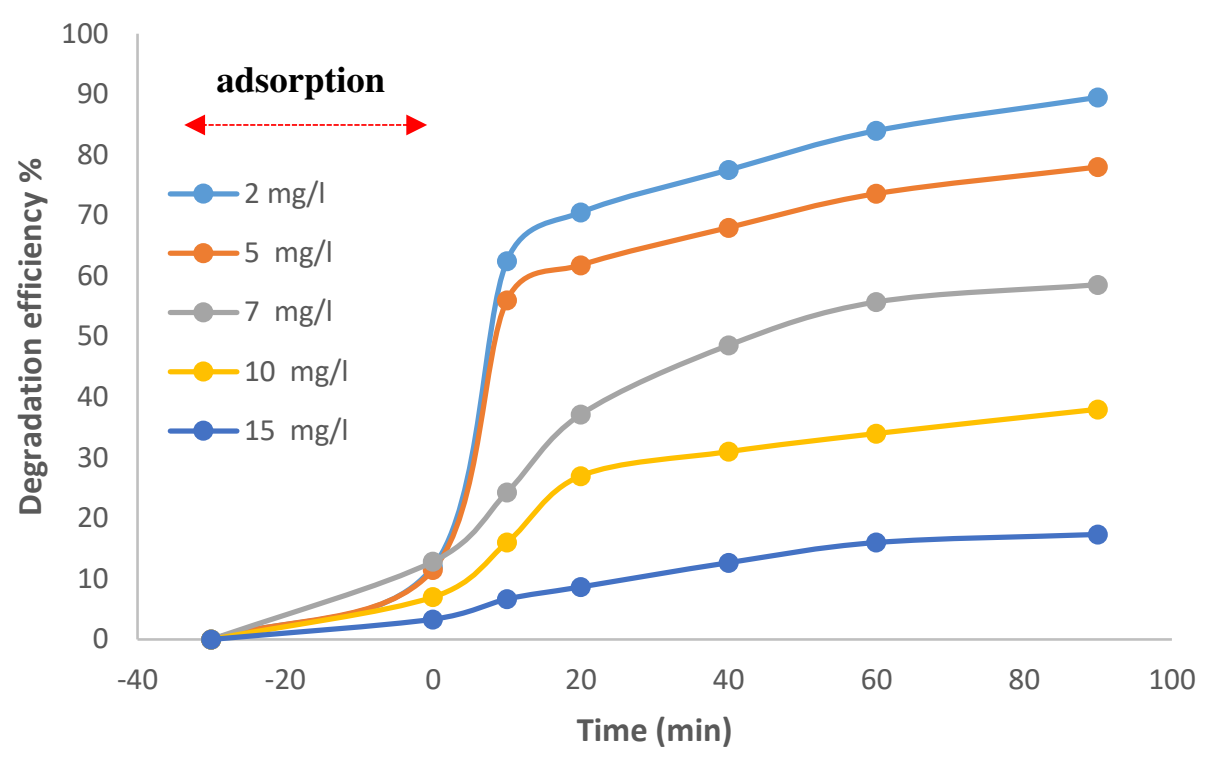

Fig. 8. Effect of HA concentration in photocatalytic degradation of HA by KCC-1/CuS (catalyst dose: $0.1 \mathrm{~g} / \mathrm{L}, \mathrm{pH}=3$ )

\subsection{Mechanism of HA degradation}

Semiconductors such as $\mathrm{CuS}$ particles have two forms of mobile carriers, including electrons in the conduction band as well as positive holes in the valence band (Arghavan et al. 2020). The bandgap is the space in the middle of the valence and conduction bands, and the energy gap sequesters the bands. As the semiconductor irradiates with more energy than the semiconductor band, these photons will switch the electron energy from the valence band to the conduction band. This process will make an electron cavity within the external shell of CuS. So, a positive hole charge $\left(\mathrm{h}^{+}\right)$and a negative electron (e $\mathrm{e}^{-}$) would produce (eq. 3), which, oxidizes $\mathrm{O}_{2}$ and $\mathrm{H}_{2} \mathrm{O}$ molecules and simultaneously produce highly active ${ }^{\circ} \mathrm{O}_{2}{ }^{-}$and ${ }^{\bullet} \mathrm{OH}$ groups (eqs.5 and 6). 
If there are no suitable electron-hole scavengers, the produced electron-hole pairs can recombine

288 the input energy as heat (Lei et al. 2021). Organic matter such as HA molecules in the aqueous

289 solution will be degraded and transformed into non-toxic byproducts such as $\mathrm{CO}_{2}, \mathrm{H}_{2} \mathrm{O}$ and 290 mineral acids (Eqs 7 to 10).

$$
\begin{aligned}
& \mathrm{UV} \text { light }+\mathrm{KCC}-1 / \mathrm{CuS} \rightarrow \mathrm{h}^{+}+\mathrm{e}^{-} \\
& \mathrm{O}_{2}+\mathrm{e}^{-} \rightarrow{ }^{\cdot} \mathrm{O}_{2}^{-} \\
& \mathrm{O}_{2}^{\cdot-}+\mathrm{H}^{+} \rightarrow{ }^{\cdot} \mathrm{HO}_{2} \\
& { }^{\circ} \mathrm{HO}_{2}+{ }^{\cdot} \mathrm{HO}_{2} \rightarrow \mathrm{H}_{2} \mathrm{O}_{2}+\mathrm{O}_{2} \\
& \mathrm{H}_{2} \mathrm{O}_{2}+\mathrm{O}_{2}^{-} \rightarrow \cdot{ }^{\cdot} \mathrm{OH}+\mathrm{OH}^{-}+\mathrm{O}_{2} \\
& \mathrm{OH}^{-}+\mathrm{h}^{+} \rightarrow \cdot \mathrm{OH}+\mathrm{H}^{+} \\
& \mathrm{H}_{2} \mathrm{O}+\mathrm{h}^{+} \rightarrow \cdot \mathrm{OH}+\mathrm{H}^{+}
\end{aligned}
$$

$\cdot \mathrm{OH}+\mathrm{HA}$ molecule $\rightarrow \mathrm{H}_{2} \mathrm{O}+\mathrm{CO}_{2}+$ mineral acids (10)

\section{Conclusion}

293 In the current study, KCC-1/CuS nanocomposite was prepared and tested for HA degradation. The 294 photocatalytic reactions were performed using UV radiation. According to the results of the 295 characterization analysis, $\mathrm{KCC}-1 / \mathrm{CuS}$ has been found to have excellent functional properties, in 296 addition to the high applicability as a photocatalyst in treatment systems. The study on HA's 297 degradation mechanism showed that the process of UV irradiation led to an excitation of the CuS 298 (excitation electron from the valence band to conduction band) which led to the generation of high 299 reactive radicals ${ }^{\circ} \mathrm{O}_{2}^{-}$and ${ }^{\circ} \mathrm{OH}$ through oxidation/reduction processes. Results showed that 300 maximum degradation efficiency of HA equal to $89.5 \%$ was achieved at the optimum condition of $3012 \mathrm{mg} / \mathrm{L} \mathrm{HA}$ concentration, $\mathrm{pH}=3$, catalyst dose $=0.1 \mathrm{~g} / \mathrm{L}$, and UV irradiation time $=90$ minutes. 
302 From this study, the photocatalytic process, using $\mathrm{KCC}-1 / \mathrm{CuS}$ under irradiation by UV light, can

303 be suggested as an efficient technology to remove HA from aqueous solutions.

304 Acknowledgments

305 The authors express their sincere thanks to the Birjand University of Medical Sciences for the 306 technical and financial support.

307 Ethical Approval

308 The Ethics Committee of Birjand University of Medical Sciences approved the study with the 309 ethical code of Ir.bums.REC.1398.18.

310 Consent to participate

$311 \quad$ Not applicable

312 Consent to publish

313 Not applicable

314 Authors Contributions

315 Mohammadi, $\mathrm{N}$ carried out the experiments and wrote the manuscript. Naghizadeh, A and

316 Allahresani, A supervised the project.

$317 \quad$ Funding

318 Birjand University of Medical Sciences has provided financial support for this research.

319 Competing interests

320 There is no competing of interest

321 Availability of data and materials

322 All data generated or analyzed during this study are included in this published article. 


\section{References}

Arghavan FS, Hossein Panahi A, Nasseh N, Ghadirian M (2020): Adsorption-photocatalytic processes for removal of pentachlorophenol contaminant using $\mathrm{FeNi}(3) / \mathrm{SiO}(2) / \mathrm{ZnO}$ magnetic nanocomposite under simulated solar light irradiation. Environmental science and pollution research international

Asgari G, Mortazavi SB, Hashemian SJ, Mosavi SG (2011): Evaluation of Performance Catalytic Ozonation Process with Activated Carbon in the Removal of Humic Acids from Aqueous Solutions. Avicenna Journal of Clinical Medicine 17, 25-33

Beyki MH, Shirkhodaie M, Shemirani F (2016): Polyol route synthesis of a Fe3O4@CuS nanohybrid for fast preconcentration of gold ions. Analytical Methods 8, 1351-1358

Bolto B, Dixon D, Eldridge R (2004): Ion exchange for the removal of natural organic matter. Reactive and Functional Polymers 60, 171-182

Dhiman M, Chalke B, Polshettiwar V (2015): Efficient Synthesis of Monodisperse Metal (Rh, Ru, Pd) Nanoparticles Supported on Fibrous Nanosilica (KCC-1) for Catalysis. ACS Sustainable Chemistry \& Engineering 3, 32243230

Doulia D, Leodopoulos C, Gimouhopoulos K, Rigas F (2009): Adsorption of humic acid on acid-activated Greek bentonite. Journal of Colloid and Interface Science 340, 131-141

Eslami A, Amini MM, Yazdanbakhsh AR, Mohseni-Bandpei A, Safari AA, Asadi A (2016): N, S co-doped TiO2 nanoparticles and nanosheets in simulated solar light for photocatalytic degradation of non-steroidal antiinflammatory drugs in water: a comparative study. Journal of Chemical Technology \& Biotechnology 91, 2693-2704

Fan S-C, Wang Y-C, Li C-L, Lee K-R, Liaw D-J, Huang H-P, Lai J-Y (2002): Effect of coagulation media on membrane formation and vapor permeation performance of novel aromatic polyamide membrane. Journal of Membrane Science 204, 67-79

Fearing DA, Banks J, Guyetand S, Monfort Eroles C, Jefferson B, Wilson D, Hillis P, Campbell AT, Parsons SA (2004): Combination of ferric and MIEX® for the treatment of a humic rich water. Water Research 38, 2551 2558

Fihri A, Cha D, Bouhrara M, Almana N, Polshettiwar V (2012): Fibrous nano-silica (KCC-1)-supported palladium catalyst: Suzuki coupling reactions under sustainable conditions. ChemSusChem 5, 85-9

Gnanaprakasam A, Sivakumar VM, Thirumarimurugan M (2015): Influencing Parameters in the Photocatalytic Degradation of Organic Effluent via Nanometal Oxide Catalyst: A Review. Indian Journal of Materials Science 2015, 601827

Hou L, Zhang H, Wang L, Chen L, Xiong Y, Xue X (2013): Removal of sulfamethoxazole from aqueous solution by sono-ozonation in the presence of a magnetic catalyst. Separation and Purification Technology 117, 46-52

Huang X, Tao Z, Praskavich Jr JC, Goswami A, Al-Sharab JF, Minko T, Polshettiwar V, Asefa T (2014): Dendritic silica nanomaterials (KCC-1) with fibrous pore structure possess high DNA adsorption capacity and effectively deliver genes in vitro. Langmuir 30, 10886-10898

Isac L, Cazan C, Enesca A, Andronic L (2019): Copper Sulfide Based Heterojunctions as Photocatalysts for Dyes Photodegradation. Frontiers in Chemistry 7

Jones MN, Bryan ND (1998): Colloidal properties of humic substances. Advances in Colloid and Interface Science $78,1-48$

Kabsch-Korbutowicz M, Majewska-Nowak K, Winnicki T (2008): Water treatment using MIEX®DOC/ultrafiltration process. Desalination 221, 338-344

Kang J, Duan X, Zhou L, Sun H, Tadé MO, Wang S (2016): Carbocatalytic activation of persulfate for removal of antibiotics in water solutions. Chemical Engineering Journal 288, 399-405

KordMostafapour F, Bazrafshan E, Belarak D, Khoshnamvand N (2016): Survey of Photo-catalytic degradation of ciprofloxacin antibiotic using copper oxide nanoparticles $(\mathrm{UV} / \mathrm{CuO})$ in aqueous environment. Journal of Rafsanjan University of Medical Sciences 15, 307-318

Lei Q, Yang S, Ding D, Tan J, Liu J, Chen R (2021): Local-interaction-field-coupled semiconductor photocatalysis: recent progress and future challenges. Journal of Materials Chemistry A

Li C, Dong Y, Wu D, Peng L, Kong H (2011): Surfactant modified zeolite as adsorbent for removal of humic acid from water. Applied Clay Science 52, 353-357

Li XZ, Fan CM, Sun YP (2002): Enhancement of photocatalytic oxidation of humic acid in TiO2 suspensions by increasing cation strength. Chemosphere 48, 453-460 
Liu J, Huang H, Huang R, Zhang J, Hao S, Shen Y, Chen H (2016): Mechanisms of CPB Modified Zeolite on Mercury Adsorption in Simulated Wastewater. Water environment research : a research publication of the Water Environment Federation 88, 490-9

Liu S, Lim M, Fabris R, Chow C, Chiang K, Drikas M, Amal R (2008): Removal of humic acid using TiO2 photocatalytic process - Fractionation and molecular weight characterisation studies. Chemosphere 72, 263271

Liu X, Zhai H, Wang P, Zhang Q, Wang Z, Liu Y, Dai Y, Huang B, Qin X, Zhang X (2019): Synthesis of a WO3 photocatalyst with high photocatalytic activity and stability using synergetic internal Fe3+ doping and superficial Pt loading for ethylene degradation under visible-light irradiation. Catalysis Science \& Technology 9, 652-658

Matilainen A, Vepsäläinen M, Sillanpää M (2010): Natural organic matter removal by coagulation during drinking water treatment: A review. Advances in Colloid and Interface Science 159, 189-197

Mesdaghinia A, MohammadTayefeh-Rafiee AHM, Vaezi F (2006): Using coagulation process in optimizing natural organic matter removal from low turbidity waters. Journal of Water and Wastewater 57, 1-7

Moein H, Nabi Bidhendi G, Mehrdadi N, Kamani H (2020): Efficiency of Photocatalytic Degradation of Humic Acid Using Magnetic Nanoparticles (Fe-doped TiO2@Fe3O4) in Aqueous Solutions. Health Scope 9, e102577

Murray CA, Parsons SA (2004): Removal of NOM from drinking water: Fenton's and photo-Fenton's processes. Chemosphere 54, 1017-1023

Ngah WSW, Fatinathan S, Yosop NA (2011): Isotherm and kinetic studies on the adsorption of humic acid onto chitosan-H2SO4 beads. Desalination 272, 293-300

Oskoei V, Dehghani MH, Nazmara S, Heibati B, Asif M, Tyagi I, Agarwal S, Gupta VK (2016): Removal of humic acid from aqueous solution using $\mathrm{UV} / \mathrm{ZnO}$ nano-photocatalysis and adsorption. Journal of Molecular Liquids 213, 374-380

Panyapinyopol B, Marhaba TF, Kanokkantapong V, Pavasant P (2005): Characterization of precursors to trihalomethanes formation in Bangkok source water. Journal of hazardous materials 120, 229-36

Polshettiwar V, Cha D, Zhang X, Basset JM (2010): High-surface-area silica nanospheres (KCC-1) with a fibrous morphology. Angewandte Chemie (International ed. in English) 49, 9652-6

Rahimi SM, Arghavan FS, Othmani A, Nasseh N (2020): Magnetically recoverable nickel ferrite coated with CuS nanocomposite for degradation of metronidazole in photocatalytic and photo fenton like processes. International Journal of Environmental Analytical Chemistry, 1-21

Reddy DHK, Lee S-M (2013): Application of magnetic chitosan composites for the removal of toxic metal and dyes from aqueous solutions. Advances in Colloid and Interface Science 201-202, 68-93

Schneider J, Matsuoka M, Takeuchi M, Zhang J, Horiuchi Y, Anpo M, Bahnemann DW (2014): Understanding TiO2 Photocatalysis: Mechanisms and Materials. Chemical Reviews 114, 9919-9986

Tabasideh S, Maleki A, Shahmoradi B, Ghahremani E, McKay G (2017): Sonophotocatalytic degradation of diazinon in aqueous solution using iron-doped TiO2 nanoparticles. Separation and Purification Technology 189, 186192

Wiszniowski J, Robert D, Surmacz-Gorska J, Miksch K, Weber J-V (2003): Photocatalytic mineralization of humic acids with TiO2: Effect of $\mathrm{pH}$, sulfate and chloride anions. International Journal of Photoenergy 5, 475943

Xie Q, Wosu SN (2016): The Effect of TaC Reinforcement on the Oxidation Resistance of CNTs/SiC CMCs. Journal of Materials Engineering and Performance 25, 874-883

Yang C-L, McGarrahan J (2005): Electrochemical coagulation for textile effluent decolorization. Journal of hazardous materials $127,40-47$

Yin Y, Yin H, Wu Z, Qi C, Tian H, Zhang W, Hu Z, Feng L (2019): Characterization of Coals and Coal Ashes with High Si Content Using Combined Second-Derivative Infrared Spectroscopy and Raman Spectroscopy. Crystals 9, 513

Yoon Y, Lueptow RM (2005): Removal of organic contaminants by RO and NF membranes. Journal of Membrane Science $261,76-86$

Zhang F, Zhuang H-Q, Zhang W, Yin J, Cao F-H, Pan Y-X (2019): Noble-metal-free CuS/CdS photocatalyst for efficient visible-light-driven photocatalytic H2 production from water. Catalysis Today 330, 203-208 
Figures
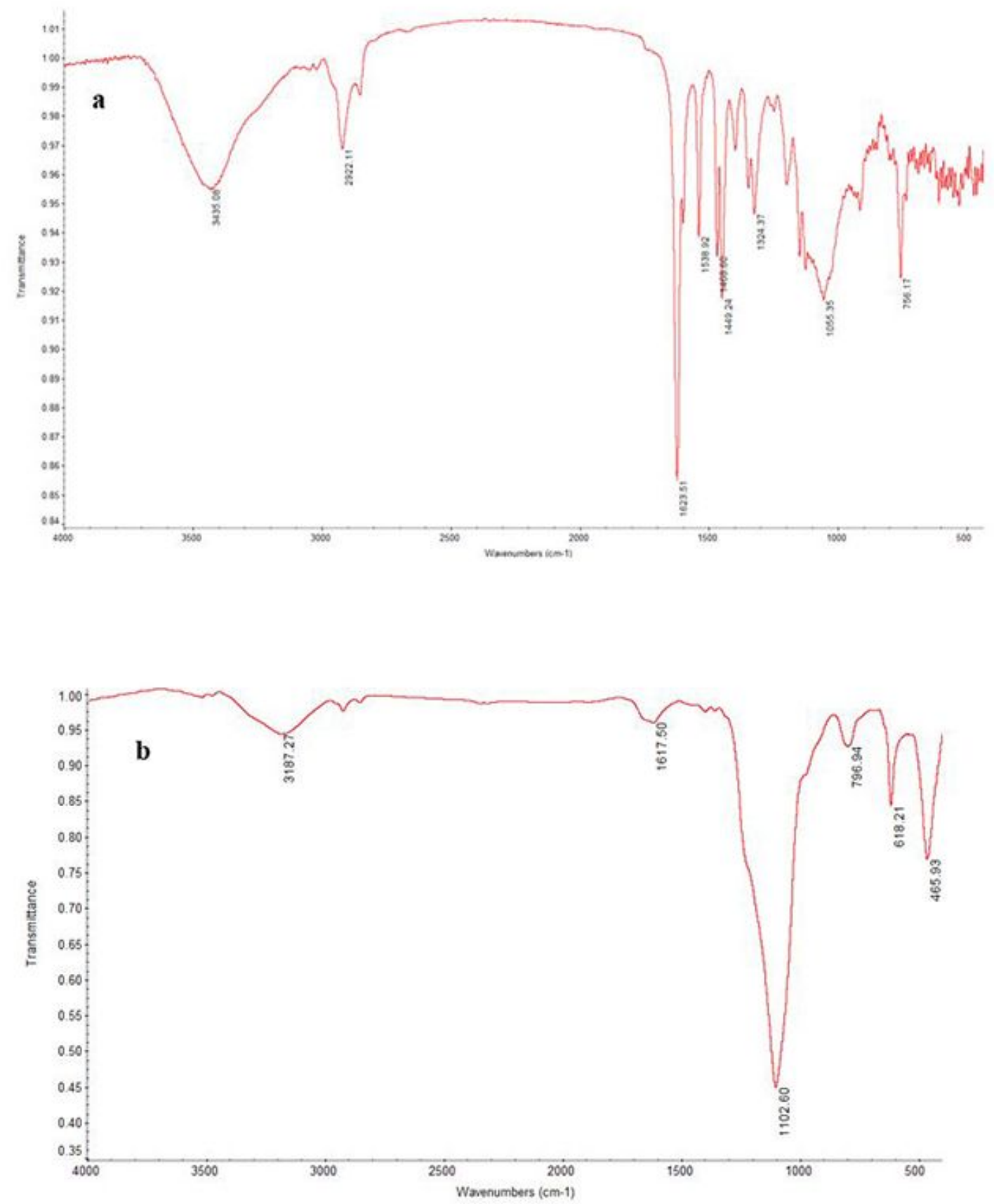

Figure 1

FTIR spectrums of KCC-1 (a) and KCC-1/CuS (b) nanocomposite 


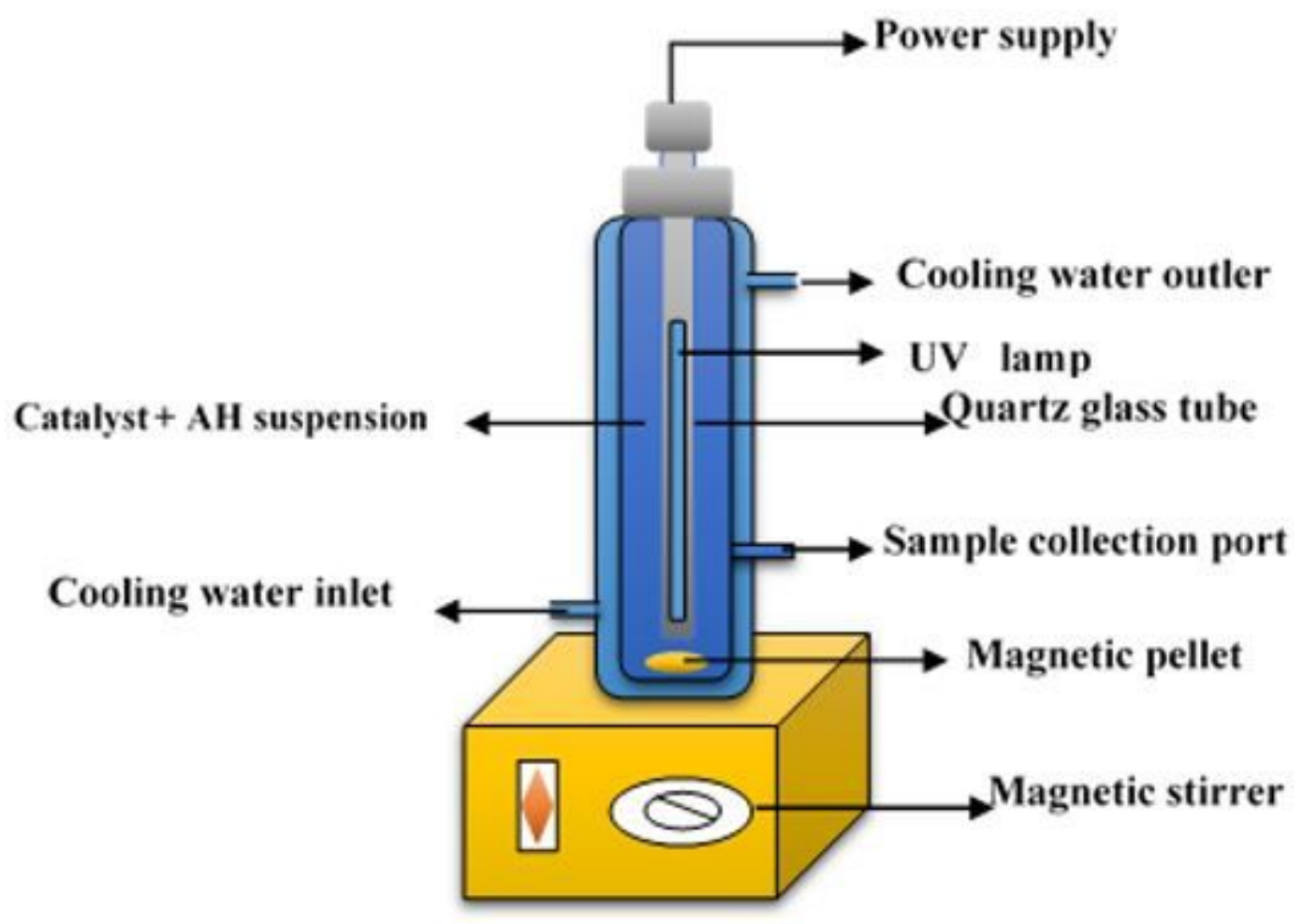

Figure 2

Schematic representation of the reactor used for the photocatalytic degradation of HA.

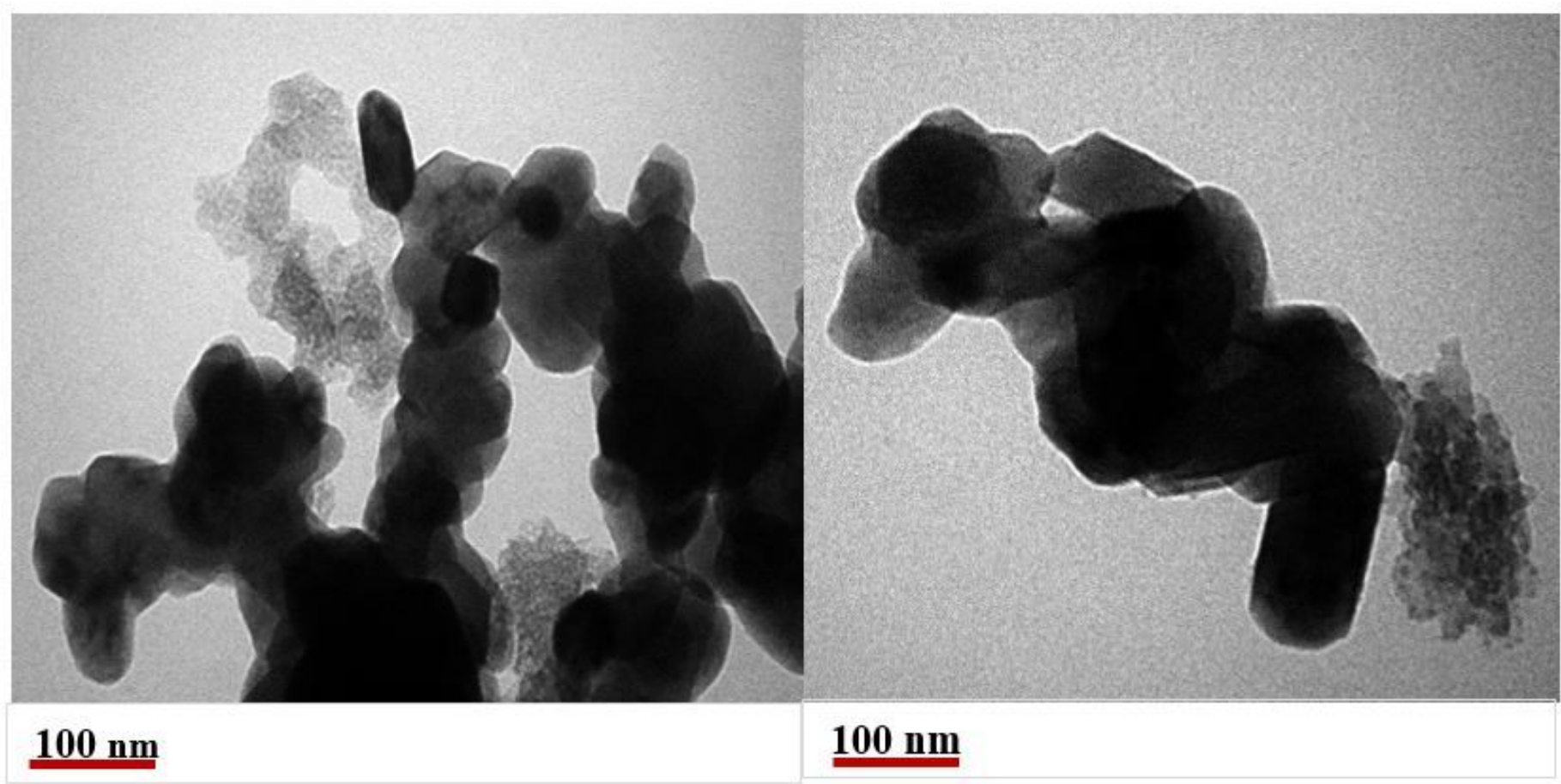

Figure 3 
TEM images of KCC-1/CUS nanocomposite

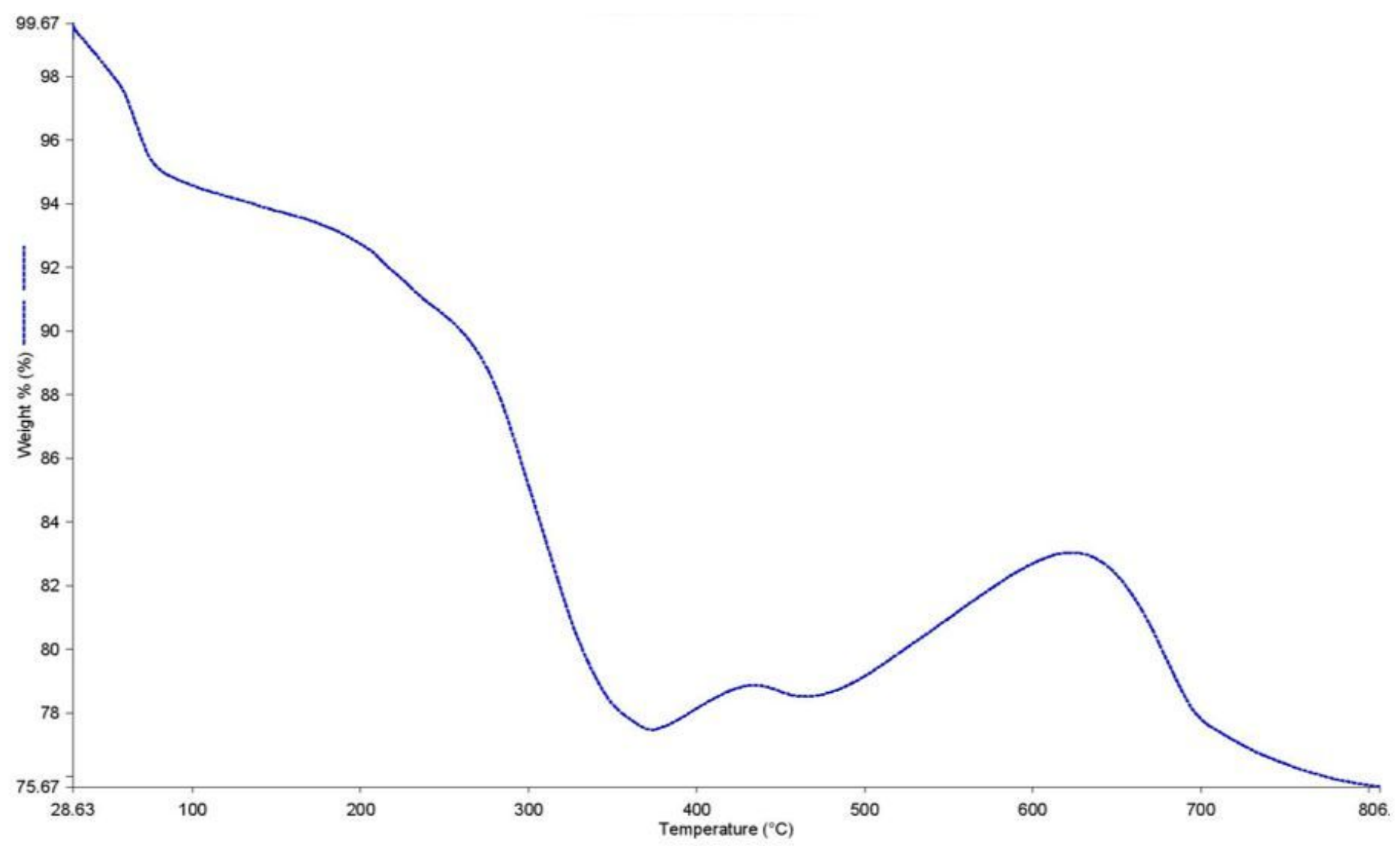

Figure 4

TGA analysis of KCC-1/CuS nanocomposite 


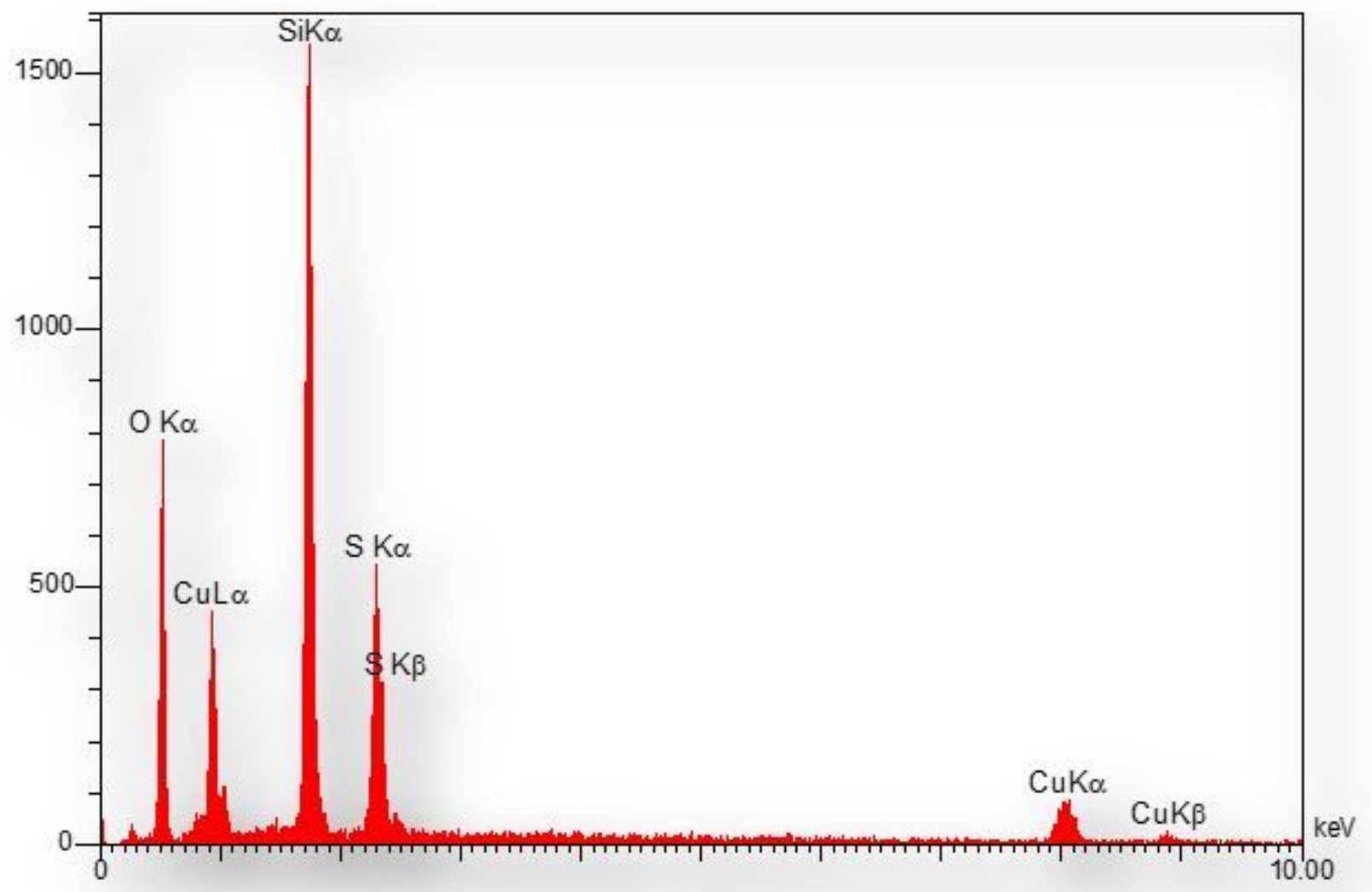

Figure 5

EDS results of KCC-1/CuS nanocomposite 


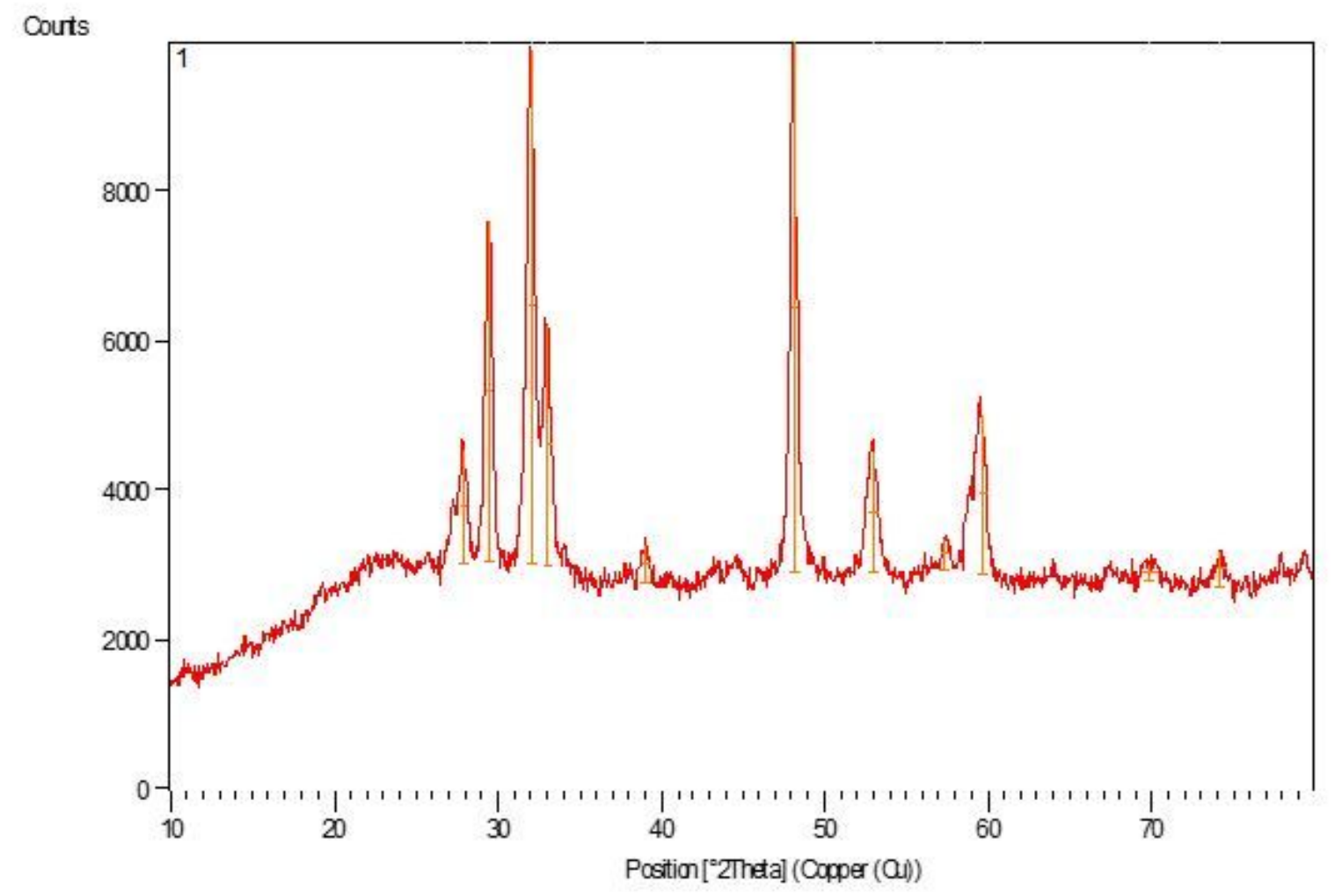

Figure 6

XRD patterns of 7 KCC-1/CuS NPs
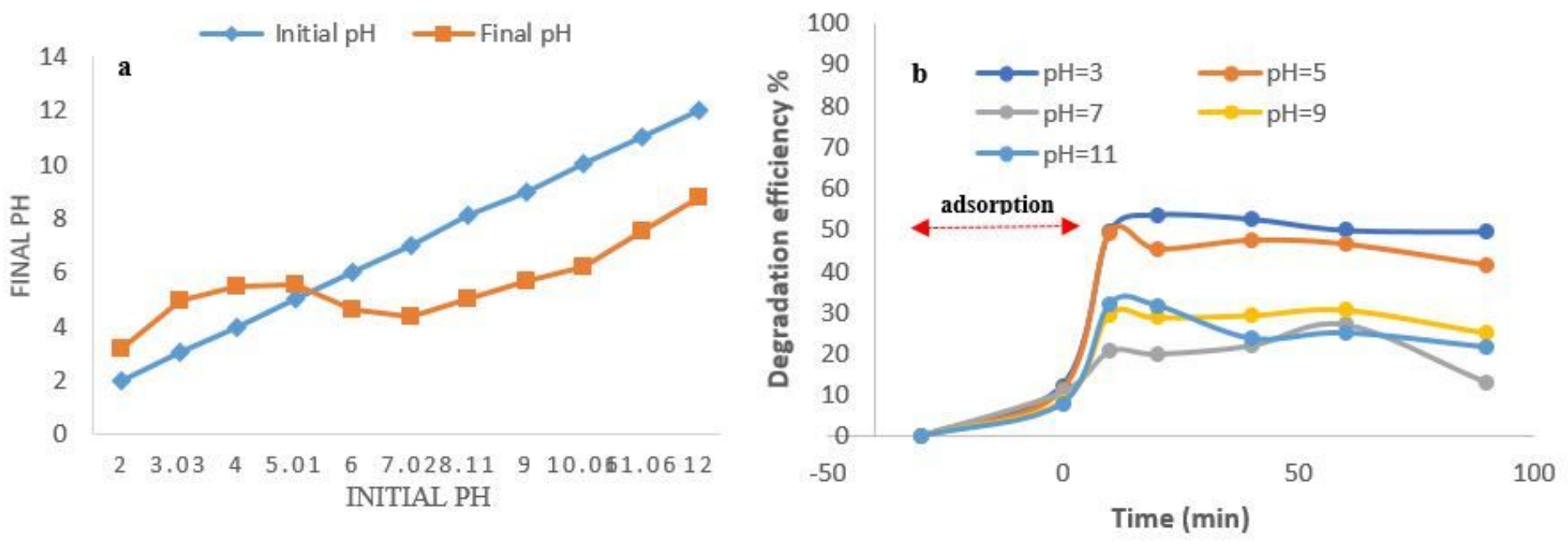

Figure 7

a) The pHzpc of KCC-1/CuS nanocomposite b) Effect of $\mathrm{pH}$ in photocatalytic degradation of HA by KCC1/CuS (HA concentration: $15 \mathrm{mg} / \mathrm{L}$, catalyst dosage: $0.03 \mathrm{~g} / \mathrm{L}$ ). 


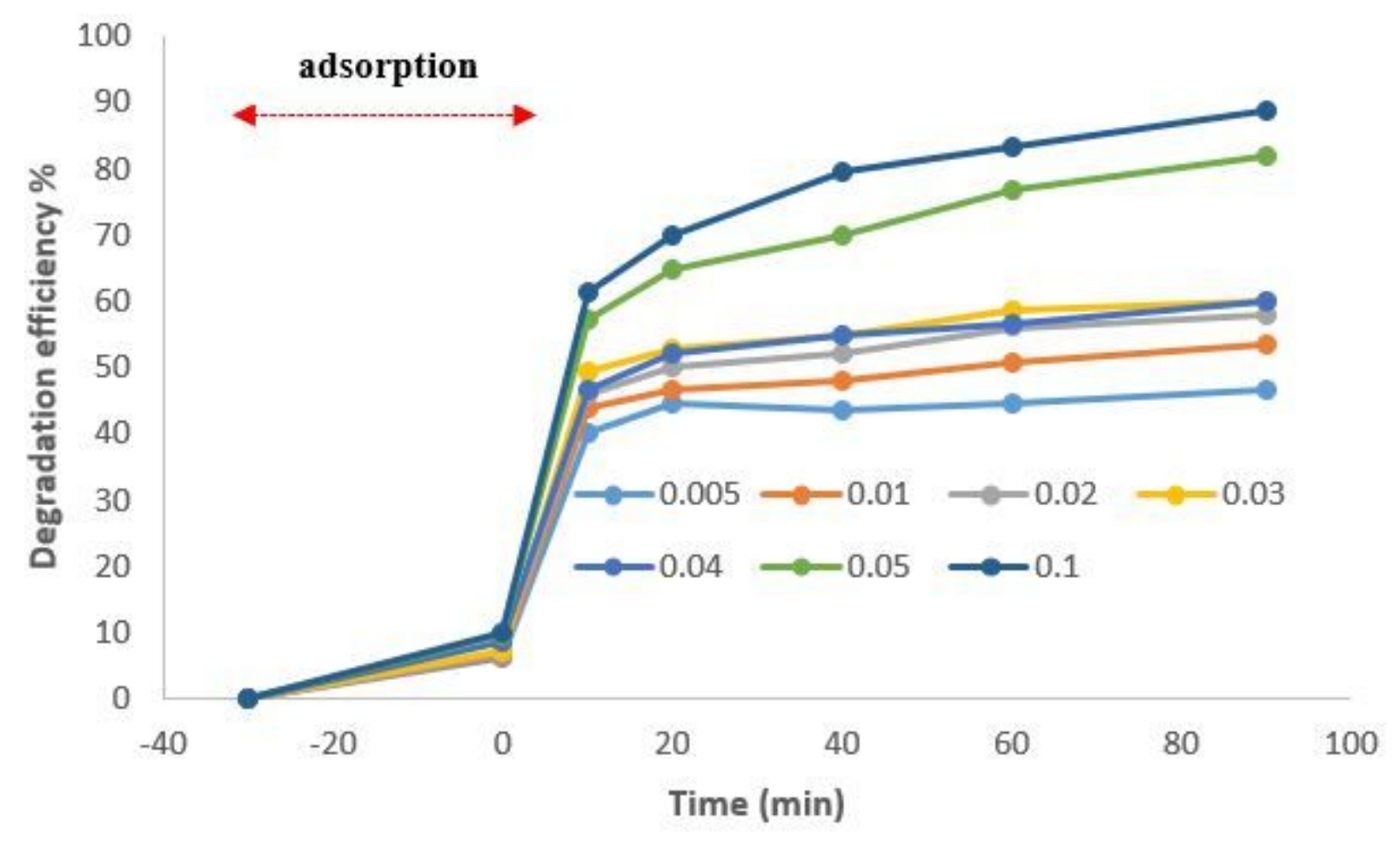

Figure 8

Effect of catalyst dosage in photocatalytic degradation of HA by KCC-1/CuS (HA concentration: $2 \mathrm{mg} / \mathrm{L}$, $\mathrm{pH}=3$ ) 


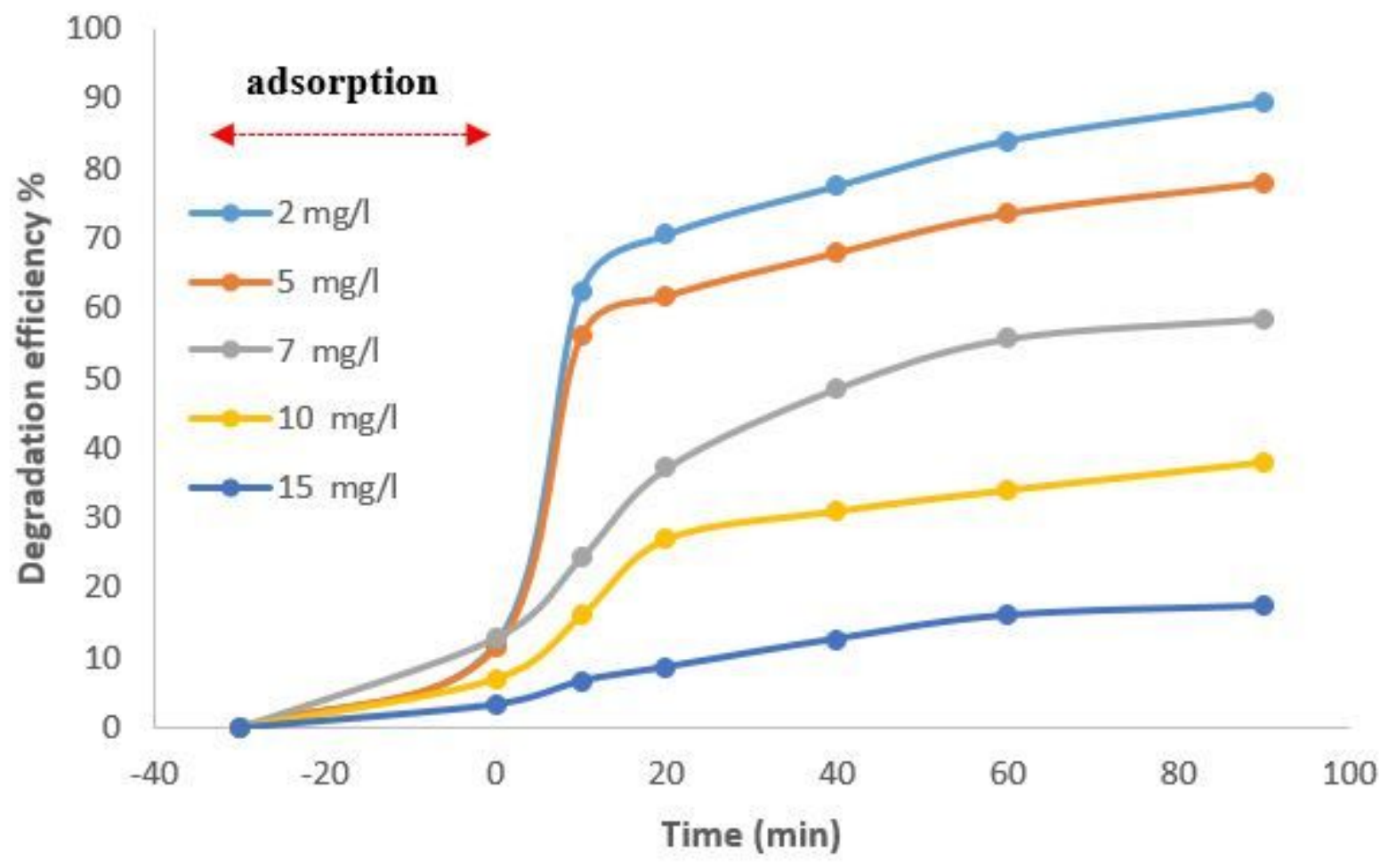

Figure 9

Effect of HA concentration in photocatalytic degradation of HA by KCC-1/CuS (catalyst dose: $0.1 \mathrm{~g} / \mathrm{L}$, $\mathrm{pH}=3$ ) 